\title{
PENILAIAN KONTRIBUSI KOMPONEN TEKNOLOGI PADA PDP KAHYANGAN KABUPATEN JEMBER
}

\section{CONTRIBUTION ASSESSMENT OF TECHNOLOGY COMPONENT AT PDP KAHYANGAN KABUPATEN JEMBER}

\author{
${ }^{1}$ Naning Retnowati, ${ }^{2}$ Financia Mayasari \\ ${ }^{1,2}$ Progam Studi Manajemen Agroindustri Manajemen Agribisnis Politeknik Negeri Jember \\ Jalan Mastrip Kotak Pos 164 Jember \\ email: nanink_wati@yahoo.com
}

\begin{abstract}
Abstrak
Teknologi telah menjadi faktor dominan dalam bisnis dan kehidupan kita. Pemilihan teknologi dapat mempengaruhi semua aspek operasi, termasuk produktifitas dan kualitas produk.Kemajuan di bidang teknologi industri mendorong setiap perusahaan meningkatkan produksinya sehingga dapat memperluas pangsa pasar dengan cara meningkatkan jumlah, jenis, serta kualitas produknya.

PDP Kahyangan adalah BUMD di Kabupaten Jember yang bergerak di bidang perkebunan. Komoditas utama perusahaan ini adalah kopi. PDP Kahyangan senantiasa berusaha untuk mempertahankan kualitas produk kopinya agar dapat memenuhi standar kualitas yang ditentukan oleh konsumen. Penggunaan tenaga kerjaprofesional yang ditunjang oleh teknologi yang sangat diperlukan dalam pengendalian proses produksi. Metode yang digunakan dalam penelitian ini adalah metoda teknometrik yang diawali dengan mengidentifikasi komponen (variabel) teknologi, yakni Technoware(T), Humanware(H), Infoware(I), dan Orgaware(O). Dalam model teknometrik dilakukan pengukuran derajat kecanggihan terhadap masing-masing komponen teknologi, menentukan state-of-the-art, menentukan kontribusi komponen teknologi, intensitas kontribusi komponen teknologi, nilai teknologi (Technology Contribution Coefficient) dinyatakan dalam gabungan keempat komponen teknologi diatas.

Hasil perhitungan menunjukkan nilai kontribusi pada setiap komponen teknologi pada PDP Kahyangan (pengolahan kopi bubuk), komponen Technoware sebesar 0.500, Humanware sebesar 0.600, Infoware sebesar 0.550, dan Orgaware sebesar 0.500. . Hasil perhitungan TCC menunjukkan bahwa PDP Kahyangan memiliki skor 0,537 dari skala $0-1$ yang berarti memiliki standar yang cukup baik dengan tingkat teknologi semi modern.
\end{abstract}

Kata kunci: Humanware, Infoware, Orgaware, Technoware, Teknometrik

\begin{abstract}
Technology has become the dominant factor in business and our lives. Selection of technology can influence all aspects of production, including productivity and product quality. The development in industrial technology aspect encourages every company increase their production so that it can expand market share by increasing the quantity, type and quality of product.

PDP Kahyangan is state-owned enterprises in Jember that cultivate plantation. The main commodity of this state-owned enterprises is coffee. PDP Kahyangan has always tried to maintain the quality of its coffee product in order to attain product quality that convenient to consumer requirement. Professional workforce utilization that are supported by technology be required in production process control.

This study using technometric model approach by identifying components technology that are Technoware(T), Humanware(H), Infoware(I), dan Orgaware $(\mathrm{O})$. In this approach assessment conducted by determining degree of technology component sophistication, valuing state-of-the-art, determining contribution of technology component, making the map of relation between the components, valuing intensity of contribution components, and then determine TCC (Technology Contribution Coefficient).

Based on the result, found that the level of of technology component sophistication in the company (PDP Kahyangan) according to Technoware is 0.500 , Humanware is 0.600 , Infoware is 0.550 , Orgaware is 0.500 and the overall level of sophistication or Total Contribution Coefficient (TCC) is approximately 0,537. At the current, level of technology at PDP Kahyangan Jember is semi modern.
\end{abstract}

Key words :Humanware, Infoware, Orgaware, Technoware, Technometric 


\section{PENDAHULUAN}

Perkembangan ilmu pengetahuan dan teknologi menyebabkan kemajuan pada bidang penerapan teknologi industri (agroindustri). Teknologi menjadi salah satu elemen penting dalam perkembangan agroindustri. Kemampuan suatu perusahaan dalam mengadopsi teknologi memberikan dampak yang sangat signifikan terhadap persaingan industri sejenis (Wahyu, 2012).

Pengertian teknologi tradisional sesungguhnya adalah teknologi yang sangat sedikit terkena sentuhan teknologi, sedangkan teknologi mutakhir sangat mengikuti perkembangan teknologi yang ada (Sa'id dkk., 2011). Selama ini banyak orang yang memahami teknologi dalam arti sempit, yang memandang teknologi hanya dari segi metode dan keteknikan saja. Teknologi sebenarnya merupakan suatu sistem yang terdiri atas komponenkomponen perangkat keras maupun lunak yang secara totalitas dibutuhkan manusia untuk memenuhi kebutuhannya (Jaya, 2004). Alkadri, dkk (1999), menyatakan bahwasanya teknologi dapat dinyatakan sebagai kombinasi dari peralatan fisik dan semua pengetahuan yang berkaitan dengan pembuatan maupun penggunaan suatu alat.

Berdasarkan entuk kombinasi teknologi, maka (Alkadri dkk., 1999) dalam (Sudaryanto, 2002)memilah teknologi menjadi empat komponen, yaitu Technoware (T), Humanware $(\mathrm{H})$, Infoware $(\mathrm{I})$, dan Orgaware $(\mathrm{O})$ yang bila disatukan menjadi THIO.Technoware merupakan fasilitas fisik, terutama segala sesuatu peralatan, perlengkapan, mesin, kendaraan bermotor, pabrik, dan infrastruktur fisik yang digunakan manusia dalam mengoperasikan transformasi. Humanware merupakan kemampuan sumber daya manusia yang meliputi pengetahuan, keterampilan, keahlian, kreatifitas, prestasi dan pengalaman seseorang atau sekelompok orang dalam memanfaatkan sumber daya alam dan sumber daya teknologi yang tersedia. Infoware merupakan seperangkat informasi yang berkaitan dengan proses prosedur, teknik, metode, teori, spesifikasi, desain, observasi, manual, dan fakta lainnya yang diungkapkan melalui publikasi, dokumen, dan cetak biru. Orgaware merupakan perangkat organisasi atau kelembagaan yang dibutuhkan untuk mewadahi fasilitas fisik, kemampuan manusia, dan fakta yang terdiri dari praktekpraktek manajemen, keterkaitan, dan pengaturan organisasi untuk mencapai hasil yang positif.

Keempat komponen teknologi ini digunakan untuk mengukur tingkat kecanggihan teknologi suatu industri. Tinggi rendahnya nilai komponen teknologi tersebut menjadi ukuran kecanggihan suatu perusahaan. Semakin tinggi nilai komponen teknologinya maka semakin tinggi pula tingkat kecanggihan suatu perusahaan.

Perusahaan Daerah Perkebunan (PDP) Kabupaten Jember adalah Badan Usaha Milik Daerah (BUMD) Pemerintah Kabupaten Jember yang bergerak dibidang Perkebunan dan beroperasi sejak tahun 1969. Komoditas utama perusahaan ini adalah kopi dan karet dengan luas lahan perkebunan kurang lebih 4.278,2239 Ha. Pada tahun 2002 PDP Kabupaten Jember melakukan diversifikasi produk biji kopi Robusta menjadi kopi sangrai dan kopi bubuk dengan merek "PDP" untuk memenuhi kebutuhan masyarakat Jember. Pada tahun 2012 produk kopi bubuk merek "PDP" diubah menjadi "PDP Kahyangan". PDP Kahyangan Jemberselalu berusaha untuk mempertahankan mutu produk kopinya agar dapat memenuhi standar kualitas yang telah ditentukan oleh konsumen. Untuk mempertahankan kualitas produk tersebut diperlukan pengendalian yang baik terhadap proses produksi. Oleh karena itu, penggunaan tenaga professional yang ditunjang oleh teknologi yang sangat diperlukan dalam pengendalian proses produksi.

PDP Kahyangan Jemberdi dalam melakukan proses pengolahan biji kopi beras menjadi kopi bubuk menggunakan kombinasi komponen teknologi yang terdiri dari Technoware, Humanware, Infoware, dan Orgaware (THIO). Pengukuran kontribusi dari masing-masing komponen teknologi bertujuan untuk menilai komponen teknologi mana yang memiliki kontribusi paling besar terhadap perusahaan serta untuk mengetahui komponen teknologi mana yang yang masih perlu dikembangkan.

\subsection{Tujuan Penelitian}

Berdasarkan rumusan masalah di atas, maka tujuan penelitian adalah sebagai berikut:

a) Untuk mengetahui penerapan komponen teknologi yang terdiri dari Technoware,Humanware, Infoware, dan Orgaware (THIO) pada proses pengolahan biji kopi beras menjadi kopi bubuk di Perusahaan Daerah Perkebunan (PDP) Kahyangan Kabupaten Jember.

b) Untuk menganalisa kontribusi dari masingmasing komponen teknologi yang terdapat pada Perusahaan Daerah Perkebunan (PDP) Kahyangan Kabupaten Jember.

\subsection{Manfaat Penelitian}

1). Manfaat bagi Perusahaan antara lain adalah :

a) Sebagai alat pendukung pengambil keputusan.

b) Dapat melakukan penilaian terhadap kontribusi dari masing-masing komponen teknologi yang telah diterapkan 

c) Dapat melakukan penilaian terhadap State of Art dari masing-masing komponen teknologi.

2). Manfaat bagi masyarakat (mahasiswa) adalah :

a) Mengetahui penerapan teknologi pada suatu perusahaan

b) Mampu menganalisa kontribusi masingmasing komponen teknologi pada suatu perusahaan

\section{METODOLOGI}

Dalam pengukuran dengan menggunakan metoda teknometrik, diawali dengan mengidentifikasi komponen (variabel) teknologi, yakni T-H-I-O dimana variabel tersebut merupakan data kualitatif yang dikuantifikasi. Komponen T-H-I-O dapat diuraikan sebagai berikut:

- Technoware yaitu fasilitas rekayasa meliputi peralatan, perlengkapan, mesin-mesin, sarana transportasi, serta infrastruktur fisik lainnya.

- Humanware yaitu kemampuan insani yang mencakup pengetahuan, keterampilan, kebijakan, kreativitas dan pengalaman.

- Infoware yaitu informasi atau dokumentasi yang berkaitan dengan proses prosedur, teknik, metoda, teori, spesifikasi, pengamatan dan linkages.

- Orgaware yaitu organisasi yang dimaksud mencakup praktek-praktek manajemen, linkages dan pengaturan organisasional.

Langkah - langkah dalam penghitungan Technology Contribution Coefficient (TCC) yang diformulasikan dengan:

TCC

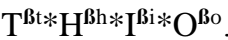
(1),

adalah sebagai berikut:

1) Deskripsi proses tansformasi suatu perusahaan

2) Menentukan batas atas (upper limit) dan batas bawah (lower limit) tingkat kecanggihan komponen teknologi dengan menggunakan scoring (1-9)

3) Mengkaji tingkat kemutakhiran (state of the art) komponen teknologi dengan scoring (110), antara lain:

Technoware $=\mathrm{STi}$

$$
=1 / 10\left(\sum \mathrm{tik} / \mathrm{kt}\right) \text {, }
$$

Dimana $\mathrm{k}=$

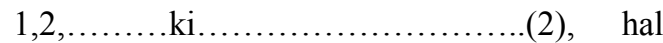
ini berlaku pula untuk penghitungan $\mathrm{SHj}$ (humanware), SI (infoware), dan SO (orgaware)

4) Menghitung kontribusi komponen

$\mathrm{Ti}=1 / 9[\mathrm{LTi}+\mathrm{STi}(\mathrm{UTi}-\mathrm{LTi})]$

$\mathrm{Hj}=1 / 9[\mathrm{LHj}+\mathrm{SHj}(\mathrm{UHj}-\mathrm{LHj})]$

I $=1 / 9[\mathrm{LI}+\mathrm{SI}(\mathrm{UI}-\mathrm{LI})]$
$\mathrm{O}=1 / 9[\mathrm{LO}+\mathrm{SO}(\mathrm{UO}-\mathrm{LO})]$

\section{HASIL DAN PEMBAHASAN}

\subsection{Analisis Teknometrik}

Untuk mengukur kandungan teknologi PDP kahyangan dalam proses pengolahan biji kopi beras menjadi kopi bubuk dilakukan dengan pendekatan teknometrik yakni mengukur faktor teknologi (Technoware), manusia/karyawan (Humanware), informasi (Infoware) dan organisasi (Orgaware). Berdasarkan pengukuran dilapangan atas komponen teknometrik diperoleh informasi sebagai berikut:

\section{Technoware}

Tipe alat mesin yang digunakan PDP dalam proses produksi (pengolahan) biji kopi beras menjadi kopi bubuk meliputi tahap penyangraian, tempering, penggilingan, sampai pengemasan adalah tergolong tipe mesin mekanik maka dari itu dapat dinilai bahwa proses pengolahan dilakukan dengan cukup baik. Proses produksi yang dilakukan berlangsung setiap hari selama bahan bahan baku masih tersedia.

Pada proses pengolahan/produksi juga dilakukan pengendalian kualitas produk kopi bubuk dengan cara melakukan proses pengawasan produksi yang dilakukan di setiap tahap proses pengolahan. Hal ini ditujukan untuk meminimalkan terjadinya cacat atau kerusakan pada produk akhir (kopi bubuk). Pengawasan yang dilakukan pada seleksi bahan baku ditujukan agar bahan baku berupa biji kopi beras sesuai dengan kriteria yakni grade WIB P tidak tercampur dengan kotoran yang dapat menurunkan mutu produk akhir. Pengawasan pada tahap roasting (penyangraian) dilakukan agar kopi biji hasil sangrai memiliki tingkat kematangan sangrai yang sesuai (tidak terlalu gosong). Begitu pula proses tempering (pendinginan) dilakukan pada waktu yang sesuai dengan yang ditentukan. Proses grinding (penggilingan) juga dikontrol agar ukuran partikel bubuk kopi sesuai dengan yang diinginkan. Pada proses pengemasan dilakukan pengawasan agar netto produk sesuai dengan yang tercantum pada label kemasan, cek pada bahan kemasan serta proses sealing juga perlu dilakukan agar kemasan produk terseal dengan baik sehingga tidak mudah bocor.

\section{Humanware}

Karyawan memahami dengan baik seluruh tugas yang harus dikerjakan dan mereka melakukannya dengan kesadaran, disiplin dan penuh tanggung jawab. Bila terjadi permasalahan mereka juga mampu menyelesaikan dengan baik. Fasilitas alat dan mesin produksi yang digunakan senantiasa dijaga/dipelihara dengan baik, misal melalui proses 
Naning Retnowati, Financia Mayasari, Penilaian Kontribusi Komponen Teknologi Pada PDP Kahyangan Kabupaten Jember

maintenance alat dan mesin yang dilakukan secara rutin. Kerjasama senantiasa dilakukan semua karyawan beserta pimpinan untuk mengupayakan tercapainya visi dan misi perusahaan.

\section{Infoware}

Pimpinan PDP (Direktur) menyampaikan informasi dengan cepat kepada seluruh karyawan terkait hal-hal yang mencakup upaya pencapaian visi dan misi perusahaan. Informasi pengerjaan produk disampaikan secara lisan dan tertulis oleh manajer bagian produksi melalui prosedur dalam penyampaian informasi. Informasi jaringan pemasaran terhadap produk kopi bubuk, dimiliki oleh manajer bagian pemasaran sehingga dapat diketahui informasi yang cukup mengenai jumlah kopi bubuk yang diinginkan oleh konsumen. Sistem pengerjaan produksi dilakukan berdasarkan job order (pesanan), dengan kualitas yang telah ditentukan oleh agen pemesan.

\section{Orgaware}

Kemampuan perusahaan dalam menciptakan lingkungan yang kondusif sebagai upaya mengadakan perbaikan dan peningkatan produktifitas dinilai cukup baik. Pimpinan juga memiliki kemampuan memotivasi karyawan melalui kepemimpinan yang efektif. Perusahaan juga mampu menjalin kerjasama dengan baik pada supplier. Perusahaan juga senantiasa menjalin hubungan yang baik dengan para pelanggan terutama pada sesi acara pameran (Jember Expo)

\subsection{Batas Tingkat Kecanggihan}

Penentuan batas atas dan batas bawah berdasarkan kriteria skor dapat dilihat pada Tabel 1 .

Tabel 1. Derajat Kecanggihan Komponen Teknologi Untuk Level Perusahaan

\begin{tabular}{|c|c|c|c|c|}
\hline $\begin{array}{c}\text { Technowar } \\
e\end{array}$ & Humanware & Infoware & Orgaware & Skor \\
\hline $\begin{array}{l}\text { Fasilitas } \\
\text { manual }\end{array}$ & $\begin{array}{l}\text { Kemampuan } \\
\text { menjalankan } \\
\text { fasilitas }\end{array}$ & $\begin{array}{l}\text { Info yang memberikan pemahaman } \\
\text { umum penggunaan fasilitas }\end{array}$ & $\begin{array}{l}\text { Perusahaan kecil, dipimpin sendiri, } \\
\text { modal kecil, tenaga sedikit }\end{array}$ & 123 \\
\hline $\begin{array}{l}\text { Fasilitas } \\
\text { mekanik/ } \\
\text { elektrik }\end{array}$ & $\begin{array}{l}\text { Kemampuan } \\
\text { memasang fasilitas }\end{array}$ & $\begin{array}{l}\text { Info yang memberi pemahaman } \\
\text { dasar penggunaan dan peragaan } \\
\text { fasilitas }\end{array}$ & $\begin{array}{l}\text { Perusahaan kecil yang telah mampu } \\
\text { meningkatkan kapabilitas dan menjadi } \\
\text { sub kontrak institusi besar }\end{array}$ & 234 \\
\hline $\begin{array}{l}\text { Fasilitas } \\
\text { penggunaan } \\
\text { umum }\end{array}$ & $\begin{array}{l}\text { Kemampuan } \\
\text { merawat fasilitas }\end{array}$ & $\begin{array}{l}\text { Info yang memungkinkan } \\
\text { menyeleksi dan memasang fasilitas }\end{array}$ & $\begin{array}{l}\text { Beberapa perusahaan bekerja sama } \\
\text { memasarkan produk secara independent }\end{array}$ & 345 \\
\hline $\begin{array}{l}\text { Fasilitas } \\
\text { penggunaan } \\
\text { khusus }\end{array}$ & $\begin{array}{l}\text { Kemampuan } \\
\text { berproduksi }\end{array}$ & $\begin{array}{l}\text { Info yang memungkinkan } \\
\text { penggunaan fasilitas secara efektif }\end{array}$ & $\begin{array}{l}\text { Beberapa perusahaan yang bekerjasama } \\
\text { mampu mengidentifikasikan produk dan } \\
\text { pasar baru melalui channel yang telah } \\
\text { ada }\end{array}$ & 456 \\
\hline $\begin{array}{l}\text { Fasilitas } \\
\text { otomatis }\end{array}$ & $\begin{array}{l}\text { Kemampuan } \\
\text { mengadaptasi }\end{array}$ & $\begin{array}{lr}\text { Info yang } & \text { memungkinkan } \\
\text { meningkatkan } & \text { pengetahuan } \\
\text { mendesain dan } & \text { mengoperasikan } \\
\text { fasilitas } & \end{array}$ & $\begin{array}{l}\text { Perusahaan mampu menjaga persaingan } \\
\text { melalui peningkatan pangsa pasar dan } \\
\text { kualitas produk } \\
\text { berkesinambungan }\end{array}$ & 567 \\
\hline $\begin{array}{l}\text { Fasilitas } \\
\text { komputeris } \\
\text { asi }\end{array}$ & $\begin{array}{l}\text { Kemampuan } \\
\text { memperbaiki }\end{array}$ & $\begin{array}{l}\text { Info yang memungkinkan terjadinya } \\
\text { perbaikan terhadap desain dan } \\
\text { penggunaan fasilitas }\end{array}$ & $\begin{array}{l}\text { Perusahaan yang dengan cepat } \\
\text { membangun kesuksesan yang stabil } \\
\text { melalui pencarian pasar baru secara } \\
\text { kontinu dan pengujian responden baru } \\
\text { terhadap perubahan lingkungan usaha }\end{array}$ & 678 \\
\hline $\begin{array}{l}\text { Fasilitas } \\
\text { terintegrasi }\end{array}$ & Kemampuan inovasi & $\begin{array}{l}\text { Info yang memberi penilaian } \\
\text { terhadap fasilitas untuk tujuan } \\
\text { spesifik }\end{array}$ & $\begin{array}{l}\text { Beberapa perusahaan mampu menjadi } \\
\text { pemimpin terkemuka dalam spesialisasi } \\
\text { usaha tertentu }\end{array}$ & 789 \\
\hline
\end{tabular}

Batas tingkat kecanggihan komponen Teknologi ditunjukkan pada Tabel 2.

Tabel 2. Batas Tingkat Kecanggihan Komponen Teknologi

\begin{tabular}{|l|c|c|}
\hline \multirow{2}{*}{ Komponen Teknologi } & \multicolumn{2}{|c|}{ Tingkat Kecanggihan } \\
\cline { 2 - 3 } & LL & UL \\
\hline Technoware & 1 & \\
Receiving & 4 & 3 \\
Roasting & 4 & 6 \\
Tempering & 4 & 6 \\
Grinding & 5 & 6 \\
Packaging & 5 \\
\hline
\end{tabular}

\begin{tabular}{|l|l|l|}
\hline Humanware & & \\
Direktur Utama & 6 & 8 \\
Direktur & 6 & 8 \\
Manajer (Ka. Bag.) & 5 & 7 \\
Staf Manajer (Ka. Sub. & 4 & 6 \\
Bag.) & 3 & 5 \\
Karyawan & & \\
\hline Infoware & 4 & 6 \\
\hline Orgaware & 4 & 6 \\
\hline
\end{tabular}

Keterangan : LL = Lower Limit (batas bawah)

$\mathrm{UL}=$ Upper Limit (batas atas)

Skor terendah pada komponen technoware terdapat pada tahap receiving. Hal ini disebabkan pada tahap receiving (penerimaan bahan baku) dilakukan secara manual, penimbangan bahanu 
kopi beras (Robusta WIB-P) yang dilakukan juga

timbangan duduk. Skor tertinggi terdapat pada tahap pengemasan (packaging)karena menggunakan mesin Korin Vertical Packaging Machine dengan fasilitas otomatis. Proses roasting, tempering dan grinding berada pada kisaran skor4-6 karena alsin yang digunakan menggunakan fasilitas penggunaan khusus yakni hanya digunakan untuk melakukan proses pengolahan biji kopi beras menjadi kopi sangrai dan bubuk.

Pada komponen humanware, skor terendah terdapat pada karyawan, yakni berkisar, yaitu sekitar 3-5 karena karyawan yang bekerja pada PDP memiliki kemampuan dalam merawat alsin produksi serta fasilitas lain dalam pabrik, maintenance alsin produksi juga dilakukan dengan cukup baik. Staf Manajer (Kepala Sub Bagian) dengan kisaran skor 4-6 karena memiliki kemampuan menyelesaikan tugas dengan cukup baik. Manajer (Kepala Bagian) berada pada kisaran skor 5-7, satu level di atas Staf Manajer karena memiliki kemampuan bekerja yang jauh lebih baik. Direktur berada pada kisaran skor 6-8 dikarenakan memiliki kemampuan dalam menyelesaikan permasalahan yang terjadi di perusahaan. Direktur utama beada pada kisaran skor yang sama dengan Direktur 6-8 karena juga memiliki kemampuan untuk memperbaiki permasalahan yang terjadi di perusahaan.

Infowareberada pada kisaran skor 4-6, karena perusahaan memiliki informasi yang memungkinkan penggunaan fasilitas secara efektif. Misal informasi terkait metode produksi biji kopi beras menjadi kopi bubuk, penggunaan alsin produksi diatur agar susut produk yang terjadi pada produk tidak terlalu besar dan pengunaan kebutuhan energi untuk proses produksi dapat dioptimalkan.

Orgawareberada pada kisaran skor 4-6 karena PDP Kahyangan mampu mengidentifikasi produk dan pasar baru dengan channel yang telah ada. Kemampuan perusahaan dalam meningkatkan produktivitas dan perbaikan kualitas produk kopi sangrai dan bubuk juga cukup baik.

\subsection{State of The Art Industry}

Penilaian state of the art industry berdasarkan kriteria yang ditentukan oleh pakar dengan skala 010. Nilai kriteria yang ditentukan untuk penilaian state of the art ini terdiri dari manual, mekanik atau elektrik, semi otomatis, dan otomatis. Penilaian dilakukan terhadap setiap proses utama yaitu meliputi komponen technoware, humanware, infoware, dan orgaware.

Tabel 3. Penilaian Penerimaan Bahan Baku (Receiving) sederhana yakni dengan menggunaka

\begin{tabular}{|l|c|c|}
\hline \multicolumn{1}{|c|}{ Kriteria } & Nilai Kriteria & Skor \\
\hline Penimbangan & Alat dan Manual & 3 \\
\hline Total & 3 \\
\hline STi & 0,3 \\
\hline
\end{tabular}

Pada tahap receiving (penerimaan bahan baku), hanya memiliki satu tahap proses yaitu penimbangan dengan skor 3, karena dilakukan secara manual.

Tabel 4. Penilaian Roasting (Penyangraian)

\begin{tabular}{|l|l|c|}
\hline Kriteria & Nilai Kriteria & Skor \\
\hline $\begin{array}{l}\text { Pengangkutan bahan } \\
\text { dengan blower }\end{array}$ & Semi otomatis & 6 \\
\hline $\begin{array}{l}\text { Penyemprotan dengan } \\
\text { air }\end{array}$ & Semi otomatis & 6 \\
\hline Total & 12 \\
\hline STi & 0,6 \\
\hline
\end{tabular}

Tahap Roasting dinilai sama-sama 5 karena tipe mesin yang digunakan secara mekanik.

Tabel 5. Penilaian Tahap Tempering

\begin{tabular}{|l|l|c|}
\hline Kriteria & Nilai Kriteria & Skor \\
\hline Pengeluaran produk alat & mekanik & 5 \\
\hline $\begin{array}{l}\text { Pergerakan } \\
\text { pengaduk secara vertikal }\end{array}$ & 5 \\
\hline Total & 10 \\
\hline STi & 0,50 \\
\hline
\end{tabular}

Tahap Tempering dinilai sama-sama 5 karena tipe mesin yang digunakan secara mekanik.

Tabel 6. Penilaian Tahap Grinding

\begin{tabular}{|l|l|c|}
\hline Kriteria & Nilai Kriteria & Skor \\
\hline Penggilingan & mekanik & 5 \\
\hline Pengeluaran produk & mekanik & 5 \\
\hline Total & 10 \\
\hline STi & 0,5 \\
\hline
\end{tabular}

Tahap Grinding dinilai sama-sama 5 karena tipe mesin yang digunakan secara mekanik.

Tabel 7. Penilaian Tahap Packaging

\begin{tabular}{|l|c|c|}
\hline Kriteria & Nilai Kriteria & Skor \\
\hline Pengemasan bahan baku & Semi otomatis & 7 \\
\hline Pengaturan netto produk & Semi otomatis & 7 \\
\hline Total & 14 \\
\hline STi & 0,70 \\
\hline
\end{tabular}

Tahap pengemasan dinilai masing-masing dengan 7 karena mesin yang digunakan semi otomatis (Korin Vertical Packaging Machine).

Tabel 8.Penilaian Humanware

\begin{tabular}{|l|l|c|c|}
\hline Kriteria & Nilai Kriteria & Skor & SHj \\
\hline Direktur Utama & Memenuhi & 8 & 0,8 \\
\hline Direktur & Memenuhi & 7 & 0,7 \\
\hline Manajer (Ka. Bag.) & Cukup memenuhi & 6 & 0,6 \\
\hline $\begin{array}{l}\text { Staf Manajer (Ka. } \\
\text { Sub. Bag.) }\end{array}$ & Cukup memenuhi & 5 & 0,5 \\
\hline Karyawan & Sedikit memenuhi & 4 & 0,4 \\
\hline
\end{tabular}

Pada komponen humanware, skor terendah terdapat pada karyawan, yakni 4 karena karyawan yang bekerja pada PDP memiliki kemampuan dalam merawat alsin produksi serta fasilitas lain dalam pabrik, maintenance alsin produksi juga dilakukan dengan cukup baik. Staf Manajer(Kepala Sub Bagian) dengan skor 5 karena 
Naning Retnowati, Financia Mayasari, Penilaian Kontribusi Komponen Teknologi Pada PDP Kahyangan Kabupaten Jember

memiliki kemampuan menyelesaikan tugas dengan cukup baik. Manajer (Kepala Bagian) berada padaskor 6 , satu level di atas Staf Manajer karena memiliki kemampuan bekerja yang jauh lebih baik. Direktur berada pada skor 7 dikarenakan memiliki kemampuan dalam menyelesaikan permasalahan yang terjadi di perusahaan. Direktur utama berada pada skor yang lebih tinggi dengan Direktur yakni 8 memiliki kemampuan lebih baik dalam memperbaiki permasalahan yang terjadi di perusahaan.

Tabel 9.Penilaian Infoware

\begin{tabular}{|l|c|c|}
\hline Kriteria & Nilai Kriteria & Skor \\
\hline $\begin{array}{l}\text { Cakupan manajemen } \\
\text { informasi perusahaan }\end{array}$ & Cukup Memenuhi & 6 \\
\hline $\begin{array}{l}\text { Cakupan jaringan } \\
\text { perusahaan }\end{array}$ & Cukup memenuhi & 6 \\
\hline Ketersediaan Database & Cukup memenuhi & 5 \\
\hline $\begin{array}{l}\text { Skema Distribusi } \\
\text { Pengawasan }\end{array}$ & Cukup memenuhi & 5 \\
\hline Total & & 22 \\
\hline SI & 0,55 \\
\hline
\end{tabular}

Pada Infoware setiap bagian dinilai cukup memenuhi, terutama pada manajemen informasi

\subsection{Perhitungan Kontribusi Komponen}

Kontribusi komponen teknologi pada PDP Kahyangan (Industri Pengolahan Kopi Bubuk) dilihat pada Tabel 11 .

Tabel 11. Kontribusi Komponen Teknologi pada PDP Kahyangan (Industri Pengolahan Kopi Bubuk)

\begin{tabular}{|l|c|c|c|c|c|}
\hline $\begin{array}{c}\text { Komponen } \\
\text { Teknologi }\end{array}$ & $\begin{array}{c}\mathrm{U} \\
\mathrm{L}\end{array}$ & $\begin{array}{c}\mathrm{L} \\
\mathrm{L}\end{array}$ & $\begin{array}{c}\text { State } \\
\text { of The } \\
\text { Art }\end{array}$ & $\begin{array}{c}\text { Kontri } \\
\text { busi } \\
\text { Dinor } \\
\text { malisa } \\
\text { si }\end{array}$ & $\begin{array}{c}\text { Kontri } \\
\text { busi } \\
\text { Total }\end{array}$ \\
\hline $\begin{array}{l}\text { Technoware } \\
\text { Receiving }\end{array}$ & $\begin{array}{c}\mathrm{U} \\
\mathrm{Ti}\end{array}$ & $\begin{array}{c}\mathrm{L} \\
\mathrm{Ti}\end{array}$ & $\mathrm{STi}$ & $\mathrm{Ti}$ & \\
\hline
\end{tabular}

\subsection{Perhitungan Intensitas Kontribusi Komponen Teknologi}

Perhitungan intensitas kontribusi komponen dilakukan untuk mengetahui tingkat kepentingan masing-masing komponen teknologi. Metode yang digunakan adalah metode pairwise comparison matrix (Satya, 1982). Penyusunan hirarki kepentingan (membandingkan $2 \beta$ dengan metode pairwise comparison matrix) ditunjukkan pada Tabel 12.

Tabel 12. Penyusunan Hirarki Kepentingan

\begin{tabular}{|c|c|c|c|c|}
\hline & T & H & I & O \\
\hline T & $\mathbf{1 , 0 0}$ & $\mathbf{2 , 0 0}$ & $\mathbf{3 , 0 0}$ & $\mathbf{2 , 0 0}$ \\
\hline H & $\mathbf{0 , 5 0}$ & $\mathbf{1 , 0 0}$ & $\mathbf{5 , 0 0}$ & $\mathbf{3 , 0 0}$ \\
\hline I & $\mathbf{0 , 3 3}$ & $\mathbf{0 , 2 0}$ & $\mathbf{1 , 0 0}$ & $\mathbf{5 , 0 0}$ \\
\hline O & $\mathbf{0 , 5 0}$ & $\mathbf{0 , 3 3}$ & $\mathbf{0 , 2 0}$ & $\mathbf{1 , 0 0}$ \\
\hline
\end{tabular}

Setelah diperoleh perhitungan AHP, langkah selanjutnya adalah dengan melakukan perhitungan terhadap nilai dan bobot $\beta$ dengan program perusahaan, karena PDP Kahyangan sangat membutuhkan informasi manajemen yang akurat, untuk pengembangan perusahaan.

Tabel 10.Penilaian Orgaware

\begin{tabular}{|l|l|c|}
\hline Kriteria & Nilai Kriteria & Skor \\
\hline Kapasitas Mesin & Cukup Memenuhi & 6 \\
\hline $\begin{array}{l}\text { Volume Penjualan } \\
\text { Pertahun }\end{array}$ & Cukup Memenuhi & 6 \\
\hline Perbaikan mesin & Cukup memenuhi & 4 \\
\hline $\begin{array}{l}\text { Pengeluaran untuk R \& } \\
\text { D tiap tahun }\end{array}$ & Cukup memenuhi & 4 \\
\hline $\begin{array}{l}\text { Tingkat Orientasi ke } \\
\text { depan }\end{array}$ & Cukup memenuhi & 5 \\
\hline Total & 25 \\
\hline SO & 0,5 \\
\hline
\end{tabular}

Pada orgaware skor tertinggi terdapat pada volume penjualan dan kapasitas mesin dalam hal ini PDP Kahyangan berusaha agar permintaan konsumen terhadap kebutuhan kopi bubuk dan sangrai semakin meningkat, sedangkan terendah adalah perbaikan mesin dan pengeluaran untuk $\mathrm{R}$ and $\mathrm{D}$ dikarenakan keterbatasan dana yang dimiliki perusahaan.

\begin{tabular}{|l|c|c|c|c|c|}
\hline Roasting & 3 & 1 & 0,30 & 0,18 & 0,500 \\
Tempering & 6 & 4 & 0,50 & 0,56 & \\
Grinding & 6 & 4 & 0,50 & 0,56 & \\
Packaging & 6 & 4 & 0,50 & 0,56 & \\
& 7 & 5 & 0,70 & 0,71 & \\
\hline Humanware & $\mathbf{U}$ & $\mathbf{L}$ & $\mathbf{S H j}$ & $\mathbf{H j}$ & \\
Direktur Utama & $\mathbf{H j}$ & $\mathbf{H j}$ & & & \\
\cline { 2 - 6 } Direktur & 8 & 6 & 0,8 & 0,84 & 0,600 \\
Manajer (Ka. & 8 & 6 & 0,7 & 0,82 & \\
Bag.) & 7 & 5 & 0,6 & 0,69 & \\
Staf & 6 & 4 & 0,5 & 0,56 & \\
Manajer(Ka.Sub & 5 & 3 & 0,4 & 0,42 & \\
. Bag.) & & & & & \\
Karyawan & & & & & \\
\hline Infoware & $\mathbf{U I}$ & $\mathbf{L I}$ & SI & $\mathbf{I}$ & \\
\cline { 2 - 7 } & 6 & 4 & 0,55 & 0,57 & 0,550 \\
\hline Orgaware & $\mathbf{U}$ & $\mathbf{L}$ & $\mathbf{S O}$ & $\mathbf{O}$ & \\
& $\mathbf{O}$ & $\mathbf{O}$ & & & 0,500 \\
\cline { 2 - 7 } & 6 & 4 & 0,55 & 0,56 & y. \\
\hline
\end{tabular}

Criteria Decision Plus. Adapun yang dihitung adalah $\beta_{\mathrm{T}}=$ technoware, $\beta_{\mathrm{H}}=$ humanware, $\beta_{\mathrm{I}}=$ infoware, $\beta_{\mathrm{O}}=$ orgaware

Jadi $\beta_{\mathrm{T}}=0,38, \beta_{\mathrm{H}}=0,33, \beta_{\mathrm{I}}=0,19, \beta_{\mathrm{O}}=0,11$

\subsection{Perhitungan komponen TCC}

Perhitungan TCC dilakukan untuk mengetahui koefisien kontribusi teknologi total dalam industri yang diuji. Hasil perhitungan ditunjukkan pada Tabel 13.

Tabel 13. Hasil Perhitungan TCC

\begin{tabular}{|c|c|c|c|}
\hline $\begin{array}{c}\text { Komponen } \\
\text { Teknologi }\end{array}$ & $\begin{array}{c}\text { Kontribusi } \\
\text { Total } \\
\text { Teknologi }\end{array}$ & Intensitas & TCC \\
\hline$e^{\text {Technowar }}$ & 0,500 & 0,380 & 0,537 \\
\hline $\begin{array}{l}\text { Humanwa } \\
\text { re }\end{array}$ & 0,600 & 0,330 & \\
\hline Infoware & 0,550 & 0,190 & \\
\hline Orgaware & 0,500 & 0,110 & \\
\hline
\end{tabular}




\subsection{Interpretasi Hasil}

Hasil perhitungan menunjukkan nilai kontribusi pada setiap komponen teknologi pada PDP Kahyangan (pengolahan kopi bubuk), komponen tertinggi ditunjukkan pada humanware dengan kontribusi total teknologi sebesar 0,600 ; diikuti oleh infoware sebesar 0,550; technoware sebesar 0,500; dan terakhir orgaware sebesar 0,500 . Kontribusi total ini diperoleh dari jumlah kontribusi yang dinormalkan dikali dengan bobot komponen teknologi. Berarti dapat dinyatakan bahwa humanware adalah komponen teknologi yang memberikan kontribusi terpenting dalam memberikan nilai tambah pada peningkatan kualitas produk kopi bubuk di PDP Kahyangan Jember, baru kemudian komponen lain secara berturut-turut adalah infoware, technoware, dan orgaware. Hasil perhitungan TCC menunjukkan bahwa PDP Kahyangan memiliki skor 0,537 dari skala 0-1 yang berarti memiliki nilai standar yang cukup baik, namun masih membutuhkan perbaikan terhadap komponen lainnya yakni infoware, technoware, dan orgaware.

\section{KESIMPULAN DAN SARAN}

\subsection{Kesimpulan}

1) Berdasarkan hasil pengamatan dapat disimpulkan bahwa kandungan teknologi yang digunakan untuk meningkatkan nilai tambah pada PDP Kahyangan dinilai sudah cukup baik. Komponen teknologi yang diterapkan PDP Kahyangan Jember, meliputi THIO dengan kontribusi masingmasing humanware dengan kontribusi total teknologi sebesar 0,600; diikuti oleh infoware sebesar 0,550; technoware dan orgaware sebesar 0,500 .

2) Humanware adalah komponen teknologi yang memberikan kontribusi terpenting dalam memberikan nilai tambah pada peningkatan kuali tas produk kopi bubuk di PDP Kahyangan Jember, baru kemudian komponen lain secara berturut-turut adalah infoware, technoware, dan orgaware. Hasil perhitungan TCC menunjukkan bahwa PDP Kahyangan memiliki skor 0,537 dari skala $0-1$ yang berarti memiliki nilai standar yang

\subsection{Saran} cukup baik.

Sebagai upaya dalam menunjang keberhasilan pencapaian tujuan perusahaannya PDP Kahyangan harus dapat meningkatkan kualitas komponen selain humanware yakni infoware, technoware, dan orgaware .

\section{UCAPAN TERIMA KASIH}

Penulis mengucapkan banyak terima kasih kepada Kementerian Riset Teknologi dan Pendidikan Tinggi serta Politeknik Negeri Jember yang telah memberikan bantuan dana demi terlaksananya penelitian ini.

\section{DAFTAR PUSTAKA}

Alkadri, Widianti A, Hadi A. R., Riyadi D. S., Arlianto D. M., Moehtadi F., Hamid, Muchdie K., Noviandi N., Sewoyo S., Prihawantoro S., Mukti S. H., Rudatin S., Ari S., Tukiyat, Warseno, Widayanto Y. 1999. Manajemen Teknologi Untuk Pengembangan Wilayah : Konsep Dasar dan Aplikasi Kebijakan.Direktorat Kebijaksanaan Teknologi untuk Pengembangan Wilayah. Badan Pengkajian dan Penerapan Teknologi.

Jaya. 2004. Analisis Kontribusi Komponen Teknologi Terhadap Kinerja Sistem Percetakan Surat Kabar Harian Umum Sumatera Ekspress Dengan Metode Teknometrik. [terhubung tidak berkala]. www.musi.ac.id [26 Agustus 2016].

Sa'id EG., Rachmayanti, dan MZ. Muttaqin. 2004. Manajemen Teknologi Agribisnis. Jakarta: Ghalia Indonesia.

Sudaryanto, 2002. Sophisticated Technology and Strategy: Analisis Internal Dalam Menyusun Intergrated Strategic Planning Pada Technological Based Business.Usahawan No. 09 Tahun XXXI September 2002

Wahyu, S. 2012. Penilaian Teknologi Untuk Menentukan Posisi Industri Pesaing Studi Kasus : PT. Sumiati Ekspor Internasional. J@TIUndip, Vol VII, No. 2, Mei 2012. Semarang : Universitas Diponegoro. 